preoccupations and actions of recovering anorexic males.

The Department of Child Psychiatr

Geraldine WALFORD

The Royal Belfast Hospital for Sick Children 180-184 Falls Road, Belfast BT126BE

\section{Photography for Anorexia Nervosa}

SIR: Body image problems have long been recognised as a major factor in anorexia nervosa (Bruch, 1962). The inability to perceive the degree of weight loss or emaciation in these patients has made treatment difficult, as patients who cannot see themselves as underweight are less likely to agree to hospital admission and treatment. We report the case of an anorexic patient who found that serial photographs of her frame provided sufficient evidence of emaciation to convince her to continue with treatment. This idea stemmed primarily from an observation of the attitudes of people to their appearance in photographs, and this was used in a particularly resistant case of anorexia to gauge her reaction to a photographic image.

Case report: Ms F., a 25-year-old lady, had an 11-year history of anorexia and amenorrhoea, and repeatedly refused admission for treatment. She was finally admitted when her weight fell to $30 \mathrm{~kg}$, and family pressures prevailed. Following admission, Ms F. continuously asserted that she was fat had an enormous stomach and legs, and was being treated inappropriately. Photographs of the patient were taken, using both front and side views, and these were presented to her. The effect was quite dramatic. Ms F. was appalled by her appearance in the photographs, and she burst into tears, immediately resolving to improve her personal appearance at whatever cost.

Prior to the photographs being taken the patient was going to leave hospital, but as a result of her exposure to pictures of her body she became very involved in her own treatment, and gained weight quite rapidly over the following weeks. She agreed to the setting of a target weight of $40 \mathrm{~kg}$, and was totally compliant with treatment. She actually requested that further photographs be taken prior to discharge, and the improvement she saw has streng thened her resolve still further. She has been discharged from our unit in good physical shape, and follow-up reveals that she is maintaining her weight. She carries her photographs to the out-patients and is pleased with her own progress.

We, suggest that the use of serial photographs of anorexic patients may well have a role in their treatment. Although previous studies using distortion techniques have tended to disprove overestimation of body size (Garner et al, 1976; Touyz et al, 1984), our initial impression is that photographs draw attention to body shape, and not to size per se. We plan to use this approach in a series of patients, and thereafter to assess the usefulness of the technique.

Alan Byrne

\section{James Connolly Memorial Hospital \\ Blanchardstown \\ Dublin 15, Ireland}

\section{References}

Bruch, H. (1962) Perceptual and conceptual disturbances in anorexia nervosa. Psychosomatic Medicine. 24, 187-194.

Garner, D. M. Garfinkel, P. E. Stancer, H C \& Moldorsky, H. (1976) Body image disturbances in anorexia nervosa and obesity. Psychosomatic Medicine, 38, 327-336.

Touyz, S. W., Beaumont, P. J. V., Collins, J. K., MCCabe, M. \& JUPP. J. (1984) Body shape perception and its disturbance in anorexia nervosa. British Journal of Psychiatry, 144, 167-171.

\section{Supportive Psychotherapy}

SIR: We were pleased to see the article by Holmes (Journal, June 1988, 152, 824-829). He asserted that supportive analytical therapy is much practiced but little described. He included two cases of successful supportive therapy with two very impaired patients, and stated that supportive therapy is an "attenuated analytical psychotherapy" that may be therapeutically effective and cost-effective in dealing with such patients.

We disagree with Dr Holmes' use of the word 'attenuated'. Supportive therapy is not a weak or diluted treatment that consists primarily of being humane to patients. It is instead an emphasis on active, but non-interpretive, interventions based on therapists' assessment of ego strength, ego structure, transference, and countertransference.

Two books have been written recently that describe supportive therapy well (Werman, 1984; Weiner, 1986). They place supportive analytical therapy on an equal footing with analytical therapy in terms of it being specifically indicated in a number of situations in which analytical therapy might also be considered, and in cases in which it is specifically indicated instead of analytical therapy. Many persons are suitable for supportive analytical therapy who are relatively emotionally healthy, but who can not or will not co-operate with the demands of analytical therapy. For example, we have suggested elsewhere that cognitive style affects the decision of what kind of therapy is potentially most useful (Weiner \& Crowder, 1986). Following an extensive cognitive evaluation of patients seen at a large public hospital, we concluded that a supportive therapy was 